\title{
Modeling carbonizing process in fluidized bed
}

\author{
M. Szota ${ }^{1}$, J. Jasinski \\ Czestochowa University of Technology, Materials Engineering Institute, \\ Biomaterials and Surface Layer Research \\ Institute, Av. Armii Krajowej 19, Czestochowa, Poland
}

\section{ABSTRACT}

This paper presents possibility of using neural networks model for designing carbonizing process in fluidized bed. This process is very complicated and difficult as multi-parameters changes are non linear and car drive cross structure is non homogeneous. This fact and lack of mathematical algorithms describing this process makes modeling properties of drives elements by traditional numerical methods difficult or even impossible. In this case it is possible to try using artificial neural network. Using neural networks for modeling carbonizing in fluidized bed is caused by several nets' features: non linear character, ability to generalize the results of calculations for data out of training set, no need for mathematical algorithms describing influence changes input parameters on modeling materials properties.

The neural network structure is designed and special prepared by choosing input and output parameters of process. The method of learning and testing neural network, the way of limiting nets structure and minimizing learning and testing error are discussed. Such prepared neural network model, after putting expected values of car cross driving properties in output layer, can give answers to a lot of questions about running carbonizing process in fluidized bed. The practical implications of the neural network models are possibility of using they to build control system capable of on-line controlling running process and supporting engineering decision in real time. The originality of this research is different conception to obtain foreseen materials properties after carbonizing in fluidized bed. The specially prepared neural networks model could be a help for engineering decisions and may be used in designing carbonizing process in fluidized bed as well as in controlling changes of this process.

\footnotetext{
${ }^{1}$ e-mail: mszota@wip.pcz.pl
} 


\section{Keywords:}

neural networks modeling, artificial intelligence, materials engineering.

\section{INTRODUCTION}

The carbonizing process in fluidized bed is multi_parameters and complicated $[1 \div 2]$, because changes of parameters during this process have non linear characteristic. At present different carbonizing techniques are used in the thermo chemical treatment. One of this is carbonizing in fluidized bed. This is characterized by high coefficient heat and mass transfer. These techniques are very often used in researching institutes and small industrial plant $[3 \div 5]$. The another problem during steel carbonizing process is non homogenous structure of research material.

\section{REFERENCES}

1 J. Jasinski, The influence of fluidized bed to steel saturation processes, WIPMiFS, Czestochowa (2003),

2 J. Jasinski, L. Jeziorski, M. Kubara, Carbonitriding of steel In fluidized beds, Heat Treatment of Metals, Vol. 12, (1988),

3 Z. Rogalski, Fluidized bed heat treatment, stage 1, Surface Engineering no 2, Warszawa (2000)

4 T. Babul, A. Nakonieczny, Z. Obuchowicz, D. Orzechowski, J. Jasinski, L. Jeziorski, T. Fraczek, R. Torbus, Industrial using of vizualization and computer control system for termo and termo-chemical treatment, Materials Engineering, 5, (2002)

5 J. Jasinski, L. Jeziorski, T. Fraczek, R. Torbus, P. Chrząstek, T. Babul, A. Nakonieczny, Z. Obuchowicz, Laboratory version of special computer system for vizualization and control F-A/O-D processes, Materials Engineering, 5, (2002) 